\title{
ANALISIS KOLEKSI DAN TATA PAMERAN RUANG INFORMASI DAN EDUKASI

\author{
STUDI KASUS KANTOR BALAI BESAR TAMAN NASIONAL GUNUNG LEUSER \\ MEDAN SUMATERA UTARA
}

\author{
Noeratri Andanwerti \\ Program Studi Desain Interior, Fakultas Seni Rupa dan Desain, Universitas Tarumanagara \\ Email: noeratria@fsrd.untar.ac.id
}

\begin{abstract}
Abstrak- Dalam menjalankan tugas pokok dalam penyelenggaraan konservasi sumber daya alam hayati dan ekosistemnyadengan salah satu fungsinya adalah penyediaan data dan informasi, promosi dan pemasaran konservasi sumber daya alam dan ekosistemnya; penyediaan data dan informasi, promosi dan pemasaran konservasi sumber daya alam dan ekosistemnya; Dalam rangka optimalisasi pelayanan publik BBTNGL akan melakukan pengembangan melalui kolaborasi pengelolaan ruang informasi dan edukasi. Informasi yang dihasilkan dan dipublikasi oleh Balai Besar TNGL masih sangat terbatas, sementara kegiatan yang dilaksanakan oleh Balai Besar TNGL dan para mitra terus meningkat aktifitasnya dilapangan dan telah menghasilkan data dan informasi yang seharusnya segera dipublikasikan. Penelitian ini merupakan penelitian kualitatif yang bertujuan menghasilkan pedoman detain untuk perancangan ruang edukasi dan informasi BBTNGL. Metode kualitatif dilakukan melalui kajian deskriptif untuk melihat karakteristik dan aktivitas pengguna yaitu pengelola dan pengunjung serta materi dan tata pameran dikaitkan dengan visi, misi dan tujuan BBTNGL. Hasil penelitian menyimpulkan bahwa koleksi dan tata pameran Ruang Informasi dan Edukasi di Kantor Balai Besar Taman Nasional Gunung Leuser Medan saat ini belum dikelola dan dirancang dengan baik.
\end{abstract}

Kata kunci: desain, interior, kolesi, pameran, informasi, edukasi, taman nasional, gunung leuser

\section{PENDAHULUAN}

Balai Besar TNGL mempunyai tugas pokok dalam penyelenggaraan konservasi sumber daya alam hayati dan ekosistemnya dengan salah satu fungsinya adalah penyediaan data dan informasi, edukasi, promosi dan pemasaran konservasi sumber daya alam dan ekosistemnya. Dalam rangka optimalisasi pelayanan publik BBTNGL akan melakukan pengembangan melalui kolaborasi pengelolaan ruang informasi dan edukasi. Informasi yang dihasilkan dan dipublikasi oleh Balai Besar TNGL rnasih sangat terbatas, sementara kegiatan yang dilaksanakan oleh Balai Besar TNGL dan para mitra terus meningkat aktifitasnya dilapangan dan telah menghasilkan data dan informasi yang seharusnya segera dipublikasikan.

Tujuan penyusunan penelitian ini adalah untuk menghasilkan pedoman bagi pelaksanaan penyusunan kegiatan pengembangan desain interior ruang informasi dan edukasi BBTNGL 2019 yang efektif dan efisien :

- Mengetahui visi, misi, tujuan, struktur organisasi dan pengelolaan lembaga BBTNGL

- Mengidentifikasi karakteristik aktivitas edukasi dan informasi yang direncanakan

- Mengidentifikasi materi koleksi, ruang dan tata pameran eksisting 
- Mengidentifikasi

parameter arsitektural ruang informasi dan edukasi

- Mengidentifikasi karakteristik dan aktivitas sasaran pengunjung

Permasalahan berkaitan dengan ruang lingkup desain interior yang akan diangkat yaitu: Bagaimana kondisi eksisting koleksi dan tata ruang edukasi dan informasi di Kantor BBTNGL? Bagaimana kebutuhan aktivitas pengelola, aktivitas pengunjung dan materi pameran serta tata ruang untuk ruang informasi dan edukasi? Bagaimana aspek fungsional, psikologi, estetis dan keamanan di ruang informasi dan edukasi ?

Informasi adalah suatu pesan yang disampaikan oleh komunikator kepada komunikan, yang berupa data, fakta, gagasan, konsep, kebijakan, aturan, standar, norma, pedoman atau acuan yang diharapkan dapat diketahui, dipahami, diyakini dan diimplementasikan oleh komunikan.

Komunikasi adalah pertukaran informasi, ide dan pengetahuan. Hal ini berupa proses dua arah dimana informasi, pemikiran, ide, perasaan atau opini disampaikan/dibagikan melalui kata-kata, tindakan maupun isyarat untuk mencapai pemahaman Bersama. Komunikasi yang baik berarti bahwa para pihak terlibat secara aktif. Hal ini akan menolong mereka untuk mengalami cara baru mengerjakan atau memikirkan sesuatu.

Komunikasi yang efektif adalah sebuah proses penyampaian pikiran atau informasi dari seseorang kepada orang lain melalui suatu cara tertentu sehingga orang lain tersebut mengerti betul apa yang dimaksud oleh penyampai pikiran-pikiran atau informasi (Komaruddin, 1994)

Edukasi adalah penambahan, pengetahuan, dan kemampuan seseorang melalui Teknik praktek belajar atau instruksi, dengan ttujuan untuk mengingat fakta atau kondisi nyata, dengan cara memberi dorongan terhadap pengarahan diri, aktif memberik informasiinformasi atau ide baru (Craven dan Hirnle, 1966, dalam Suliha, 2002)

Ruang edukasi dan informasi adalah ruang yang memiliki fungsi mengkomunikasikan informasi dan memberikan pengetahuan untuk tujuan tertentu, agar sasaran masyarakat memiliki pengetahuan baru melalui informasi dan pengetahuan yang diberikan.

Sebagai ruang informasi dan edukasi perlu memperhatikan hal-hal sebagai berikut :

a. Aspek fungsional: Penataan ruang harus mampu mendukung kinerja pengelolaan secara keseluruhan baik bagi petugas maupun 
bagi pengunjung serta penataan interior dapat tercipta secara optimal

b. Aspek psikologis: Bertujuan agar pengguna ruang edukasi dan informasi merasa nyaman dan leluasa bergerak di ruang informasi dan edukasi

c. Aspek estetis: ruang perlu memperhatikan faktor keindahan, keserasian, kerapian dan kebersihan untuk menunjang daya tarik, pengalaman dan kenyamanan pengunjung selama berada di dalam ruang.

d. Aspek keamanan: Keamanan materi koleksi arus dijaga dengan baik, agar terhindari dari kerusakan secara alami dan kerusakan / kehilangan bahan karena faktor manusia (Wiji Suwarno, 2011: 45-46).

\section{METODE}

Penelitian ini memilih objek di Kantor Balai Besar Taman Nasional Gunung Leuser (BBTNGL) Jl. Selamat No. 137 Kelurahan Siti Rejo III Medan Amplas, Medan, 20219, Sumatera Utara.

Pengambilan data dilakukan secara langsung maupun tidak langsung. Pengambilan data secara langsung dilakukan di lokasi Kantor BBTNGL di Medan. Sementara secara tidak langsung, data didapat melalui wawancara narasumber Kepala Balai dan Staf dan mitra.

Pemilahan dan penyusunan data, yang dilanjutkan dengan proses analisis, dilakukan di kampus FSRD Untar oleh tim peneliti, dengan melibatkan tim mahasiswa maupun dengan mendapatkan masukan dari rekanrekan dosen FSRD Untar melalui forum diskusi terbatas.

Penelitian ini menggunakan analisis deskriptif dengan menggunakan pendekatan kualitatif yang bertujuan untuk menggambarkan dan mendeskripsikan keadaan suatu fenomena dengan menganalisis data yang ditemukan di lapangan sebagai hasil penelitian. Data yang bersifat kualitatif digunakan teknik analisis deskriptif dengan mengembangkan kategori-kategori yang relevan dengan dasar penelitian dan didasarkan pada teori-teori yang relevan. Metode kualitatif dilakukan melalui kajian deskriptif untuk melihat karakteristik dan aktivitas pengguna yaitu pengelola, mitra dan pengunjung, mengetahui fungsi, karakeristik fisik, psikologis dan estetik dari bangunan, interior, furnitur serta materi koleksinya.

Data dalam penelitian ini terdapat dua jenis data yaitu data primer dan data sekunder. Data primer merupakan data yang diambil langsung dari hasil observasi lapangan berupa data fisik maupun non-fisik. Data fisik yang dimaksud pada penelitian ini mengacu pada data bangunan, ruang dan furniture serta materi koleksi. Data non-fisik adalah data-data mengenai nilai-nilai dan visi misi BBTNGL, karakteristik dan aktivitas pengguna yang 
menjadi pendekatan ruang informasi dan edukasi yang didapat melalui wawancara dengan pengelola.

Data sekunder adalah data yang didapat dari berbagai referensi atau pustaka yang mendukung, seperti data sejarah, hasi penelitian sebelumnya mengenai objek dan ruang informasi dan edukasi secara umum.

Penelitian ini mengambil studi kasus desain interior ruang informasi dan edukasi BBTNGL, yang memiliki fungsi memberikan informasi dan memberikan edukasi dan berperan dalam pembangunan karakter bangsa khususnya yang memiliki wawasan tentang konservasi alam

Sebagai suatu metode kualitatif, studi kasus memiliki beberapa analisis, yaitu :

- Menyajikan pandangan pihak Lembaga BBTNGL sebagai pengelola dan pihak yang menyelenggarakan fungsi informasi dan edukasi

- Menyajikan uraian tentang objek: desain bangunan dan desain interior ruang eksisting

- Menunjukkan karakteristik sasaran pengunjung sebagai pertimbangan terhadap setting lingkungan fisik

- Terbuka bagi penilaian atas standar/pedoman perencanaan tata ruang dan fasilitas informasi dan edukasi terhadap aspek desain bangunan dan desain interiornya

Berdasarkan hasil data observasi, wawancara, dan dokumentasi tersebut dianalisa data kualitatif deskriptif adalah sebagai berikut:

a. Reduksi data yaitu data yang diperoleh dari lapangan yang banyak dan kompleks maka perlu dilakukan analisis data melalui reduksi data. Reduksi data dengan cara merangkum, memilih halhal pokok, memfokuskan hal-hal yang penting dan membuang hal-hal yang dianggap kurang penting.

b. Penyajian data yaitu data yang sudah direduksi disajikan dalam bentuk uraian singkat berupa teks yang bersifat naratif. Melalui penyajian data tersebut maka data akan mudah dipahami sehingga memudahkan rencana kerja selanjutnya.

c. Penarikan kesimpulan yaitu data yang sudah disajikan dianalisis secara kritis berdasarkan fakta-fakta yang diperoleh dilapangan. Penarikan kesimpulan dikemukakan dalam bentuk naratif dan program (pedoman desain) sebagai jawaban dari rumusan masalah. 


\section{HASIL DAN PEMBAHASAN}

\section{A. Analisis Ruang Informasi dan Edukasi Eksisting}

Kantor Balai Besar Taman Nasional Gunung Leuser beralamat di Jalan JI. Selamat No.137, Sitirejo III, Kecamatan Medan Amplas, Kota Medan, Sumatera Utara.

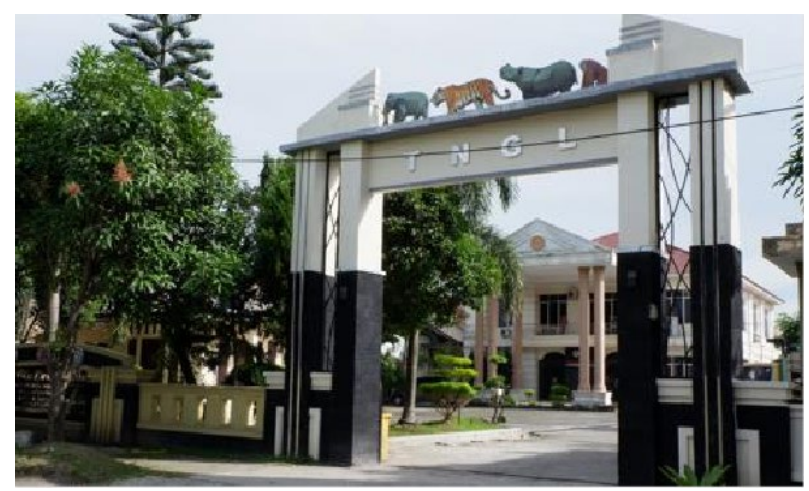

Gambar 1. Kantor Balai Besar Taman Nasional Gunung Leuser Medan

Balai Besar TNGL selama ini dalam memberikan pelayanan dan informasi kepada masyarakat masih bersifat konvensional, artinya masih mengikuti kebiasaan • kebiasaan yang lazim digunakan di kantor-kantor pemerintahan, dan belum interaktif.

Sarana prasarana yang digunakan masih terbatas berupa perpustakaan, ruang display, banner, leaflet dan lain sebagainya serta dilakukan secara mandiri dan belum melibatkan pihak lain dan saat ini ruang informasi di Balai Besar TNGL memiliki ukuran luas $16,2 \mathrm{~m} \times 15,11 \mathrm{~m}$.

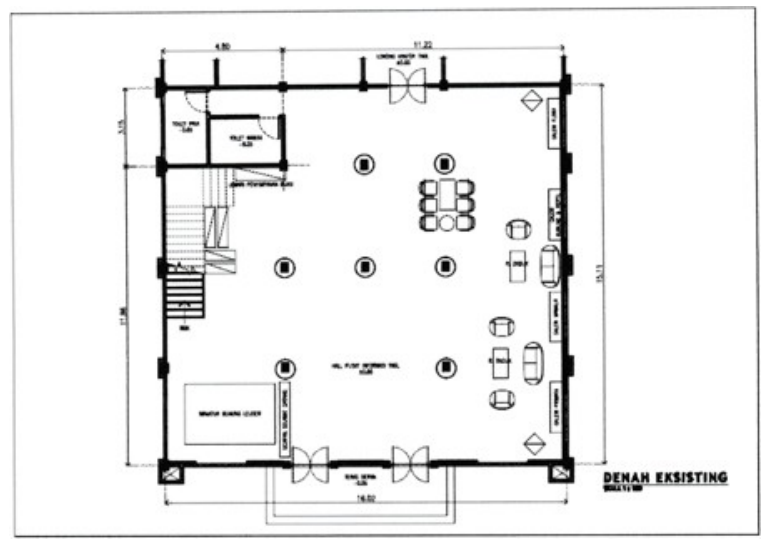

Gambar 2. Denah Ruang Eksisting

Organisasi Ruang eksisting terdiri dari

1. Main Entrance

2. Lobby

3. Ruang Tamu

4. Area Diplay

5. Storage

6. Toilet

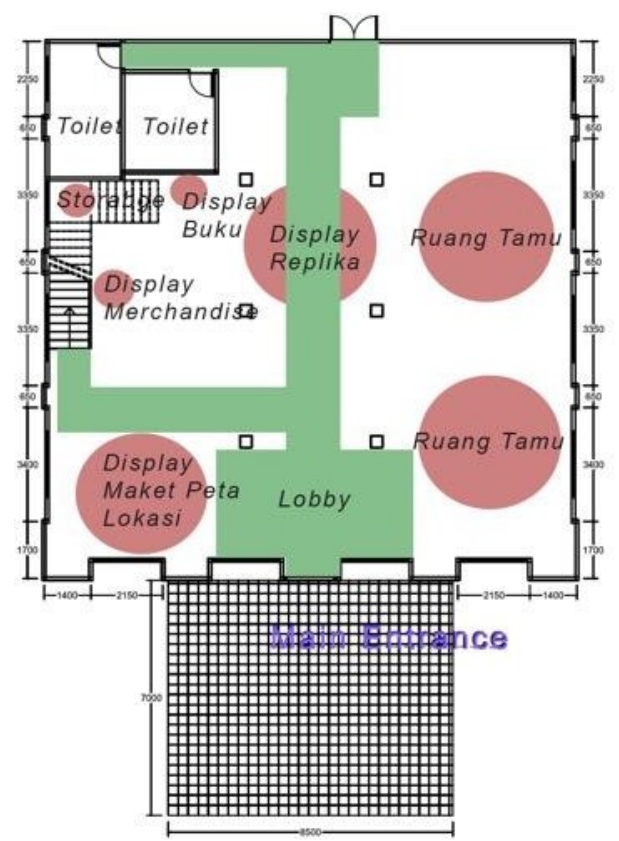

Gambar 3. Organisasi Ruang Eksisting 
Kondisi eksisting ruang dapat dilihat pada foto dokumentasi berikut ini :

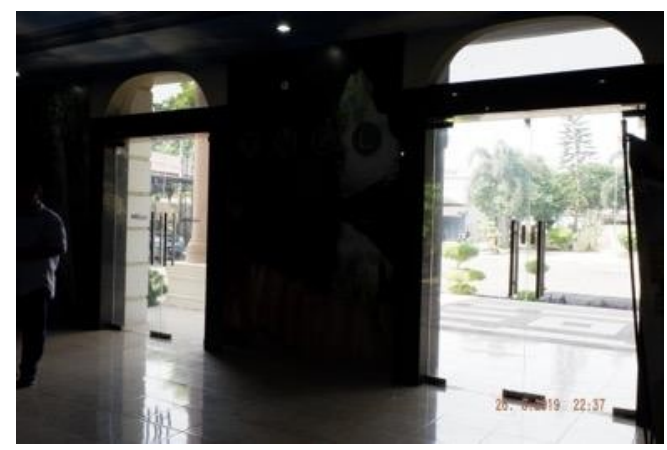

Gambar 4. Main Entrance

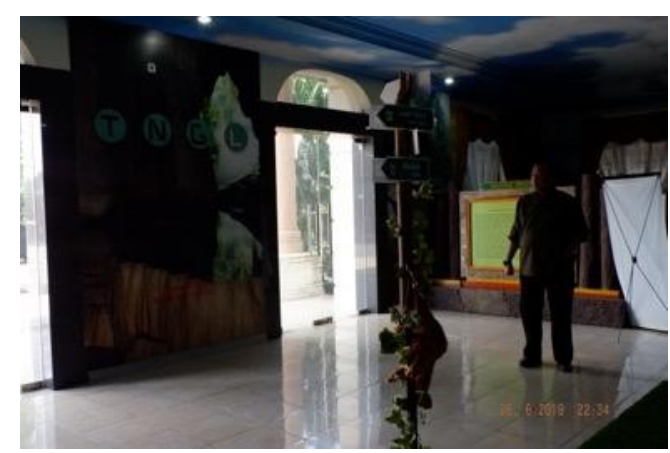

Gambar 5. Lobby

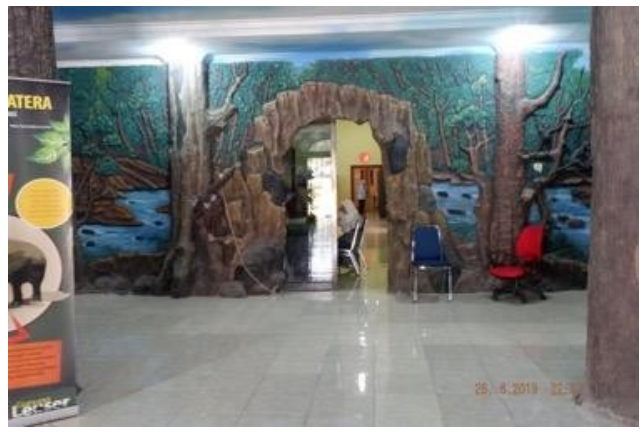

Gambar 6. Dekorasi Mural pada Dinding

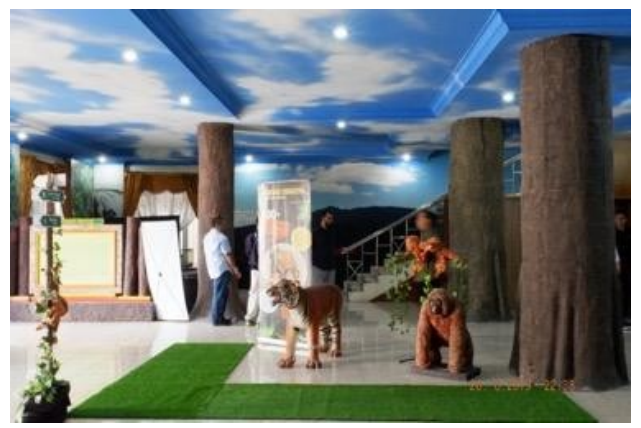

Gambar 7. Area Display Replika Satwa

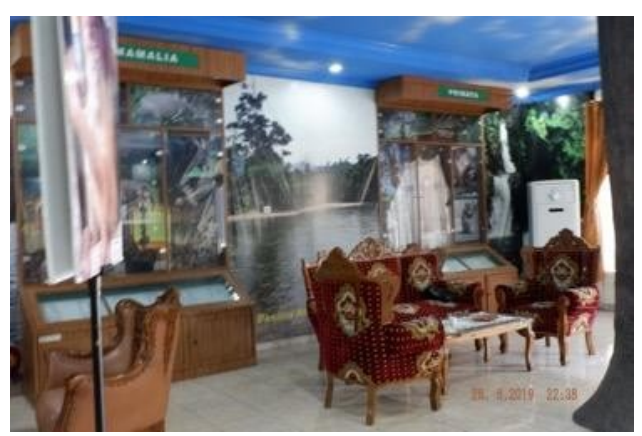

Gambar 8. Ruang Tamu dilengkapi fasilitas duduk

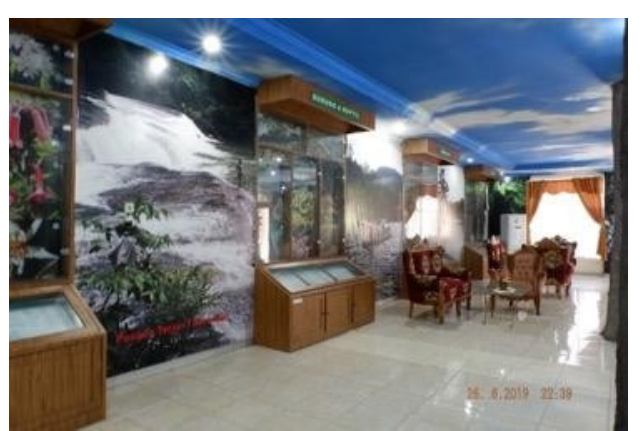

Gambar 9. Pengaturan Lemari Pajang dan Dokumentasi Foto Alam Taman Nasional Gunung Leuser

B. Analisis Fungsi (Aktivitas) \& FASILITAS Ruang Informasi Dan Edukasi

Berdasarkan hasil wawancara dan pengamatan di lapangan dapat dideskripsikan fungsi-fungsi aktivitas sebagai berikut:

1. Tersedianya ruang informasi dan edukasi yang representatif sebagai suatu wadah yang digunakan untuk memberi informasi dan edukasi berkenaan dengan pengelolaan kawasan TNGL yang dilengkapi dengan bahan dan peralatan yang lebih interaktif sehingga menjadi daya tarik bagi masyarakat. 
2. Ruang informasi dan edukasi di Balai Besar Taman Nasional Gunung Leuser merupakan show window materi/koleksi

3. Area Publik / ruang tunggu bagi tamu ataupun pengunjung Balai Besar TNGL.

4. Area / Ruang untuk tempat pelayanan perizinan.

5. Ruang perpustakaan untuk menyimpan buku dan bulletin tentang Taman Nasional Gunung Leuser dan bukubuku lainnya.

6. Area publikasi tentang TNGL melalui peralatan display yang lebih interaktif.।

7. Ruang sebagai sarana promosi kegiatan dan bahan pameran mitra TNGL

8. Ruang pajang souvenir baik dari BBTNGL maupun dari Mitra TNGL.

9. Ruang Pelayanan publik yang optimal melalui kolaborasi pengelolaan ruang informasi dan edukasi dengan dukungan sarana dan prasarana yang memadai baik berupa ruang, peralatan dan manajemen pengelolaan

C. Analisis Kebutuhan Minimum Peralatan Pendukung Ruang Informasi Dan Edukasi

Berdasarkan pengamatan dan wawancara, Ruang Informasi dan Edukasi diperlukan fasilitas sebagai berikut:

$$
\text { Tabel 1. Analisis Kebutuhan Ruang Dan Fasilitas }
$$

\begin{tabular}{|c|c|c|c|}
\hline No & Fungsi Ruang & Fasilitas yang dibutuhkan & Jumlah Unit \\
\hline \multirow[t]{9}{*}{1} & Fungsi Ruang & Komputer (PC) & 3 Unit \\
\hline & $\begin{array}{l}\text { Tunggu (customer } \\
\text { service) }\end{array}$ & Multimedia & \\
\hline & & Printer A4 All In One & 1 Unit \\
\hline & & Meja & 1 Unit \\
\hline & & Kursi & 3 Unit \\
\hline & & UPS & 3 Unit \\
\hline & & $\begin{array}{l}\text { Credenza/Rak Buku } \\
\text { Majalah/buku }\end{array}$ & 1 unit \\
\hline & & Sofa/kursi tunggu & 1 Set \\
\hline & & Mini Bar & 1 Set \\
\hline \multirow[t]{6}{*}{2} & Fungsi Pelayanan & Komputer (PC) & 1 unit \\
\hline & Perizinan & Multimedia & \\
\hline & & Printer All In One & 1 Unit \\
\hline & & Meja & 1 unit \\
\hline & & Kursi & 3 Unit \\
\hline & & Filing Cabinet & 1 Unit \\
\hline \multirow[t]{2}{*}{3} & $\begin{array}{l}\text { Fungsi } \\
\text { Perpustakaan }\end{array}$ & Rak Buku & 3 Unit \\
\hline & & Meja/kursi baca & $\begin{array}{l}1 \text { Set } \\
\text { (kapasitas 5- } \\
6 \text { orang) }\end{array}$ \\
\hline \multirow[t]{6}{*}{4} & $\begin{array}{l}\text { Fungsi Publikasi, } \\
\text { promosi serta } \\
\text { media } \\
\text { merchandise }\end{array}$ & Touch Scren Table & 1 Unit \\
\hline & & Wall Mount LCD Display & 3 Unit \\
\hline & & LCD Video Wall & 3 Unit \\
\hline & & Audio & 1 Unit \\
\hline & & Rak Kaea & 3 Unit \\
\hline & & $\begin{array}{l}\text { Lemari gantung untuk } \\
\text { Penyimpanan }\end{array}$ & 3 Unit \\
\hline
\end{tabular}

D. Analisis Kebutuhan Personil Pengelola Ruang Informasi Dan Edukasi

Berdasarkan wawancara, organisasi dan pengelolaan di Kantor Balai Besar Taman Nasional Gunung Leuser dapat dijelaskan melalui gambar struktur organisasi dibawah ini, yang mana Ruang Informasi dan Edukasi dibawah Kelola dan layanan Bagian Tata Usaha. 


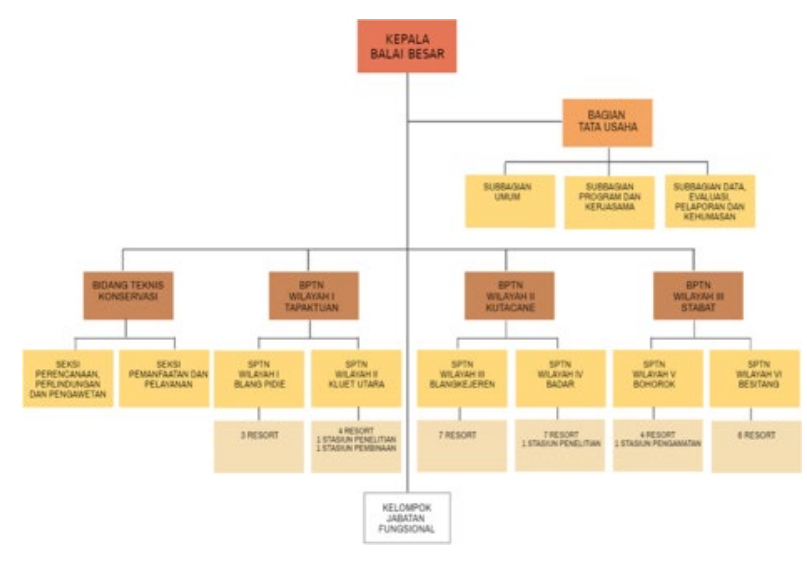

Gambar 10. Struktur Organisasi KBBTNGL

Saat ini personil pada bidang teknis konservasi BBTNGL sebanyak 20 orang staf tetap dan 1 orang mitra kerja. Analisis personil untuk pengelola Ruangan Informasi dan Edukasi di Kantor BBTNGL sebagai berikut:

Tabel 2. Analisis Personil Unit Ruang Informasi Dan Edukasi

\begin{tabular}{|c|c|c|c|}
\hline NO & Uraian & JUMLAH & Sumber \\
\hline 1 & Unit Pelayanan & 1. Office staf & \multirow{5}{*}{$\begin{array}{l}\text { BBTNGL dan Mitra } \\
\text { Kerja }\end{array}$} \\
\hline & & 2. Interpreuner & \\
\hline 2 & $\begin{array}{l}\text { Unit Pelayanan dan } \\
\text { Perizinan }\end{array}$ & $\begin{array}{l}\text { Seksi Pelayanan dan } \\
\text { Pemanfaatan BBTNGL }\end{array}$ & \\
\hline \multirow[t]{2}{*}{3} & $\begin{array}{l}\text { Unit Updating data dan } \\
\text { layout display }\end{array}$ & 1. Tim UDIK BBTNGL & \\
\hline & & 2. Desainer & \\
\hline
\end{tabular}

E. Analisis Karakteristik Sasaran Pengunjung Ruang Informasi dan Edukasi

Sasaran pengunjung fasilitas ini direncanakan berdasarakan kelompok usia, tujuan dan pekerjaan

\begin{tabular}{|c|c|c|c|}
\hline No & $\begin{array}{c}\text { Kelompok } \\
\text { Sasaran }\end{array}$ & $\begin{array}{l}\text { Karakteristik } \\
\text { Pengunjung }\end{array}$ & Keterangan \\
\hline 1 & USIA & $\begin{array}{l}\text { Anak-anak (s.d. } \\
12 \text { tahun) } \\
\text { Dewasa }\end{array}$ & $\begin{array}{l}\text { Fasilitas ini } \\
\text { menambahkan } \\
\text { sasaran anak- } \\
\text { anak untuk } \\
\text { dapat } \\
\text { mengakses. }\end{array}$ \\
\hline 2 & TUJUAN & $\begin{array}{l}\text { Informasi } \\
\text { Penelitian } \\
\text { Dinas } \\
\text { Rekreasi }\end{array}$ & $\begin{array}{l}\text { Saat ini tujuan } \\
\text { informasi, } \\
\text { dinas dan } \\
\text { penelitian yang } \\
\text { paling } \\
\text { dominan, dan } \\
\text { berupaya untuk } \\
\text { meningkatkan } \\
\text { pengunjung } \\
\text { dengan tujuan } \\
\text { rekreasi }\end{array}$ \\
\hline 3 & PROFESI & $\begin{array}{l}\text { Pelajar } \\
\text { (SD,SMP,SMA) } \\
\text { Mahasiswa } \\
\text { Peneliti } \\
\text { Umum }\end{array}$ & $\begin{array}{l}\text { Mahasiswa dan } \\
\text { Peneliti yang } \\
\text { lebih banyak } \\
\text { mengakses } \\
\text { fasilitas ini }\end{array}$ \\
\hline
\end{tabular}

\section{SIMPULAN}

Hasil penelitian ini dapat disimpulkan bahwa keberadaan Ruang Informasi dan Edukasi sangat penting untuk mendukung fungsi Balai Besar Taman Nasional Gunung Leuser Medan untuk penyediaan data dan informasi, edukasi, promosi dan pemasaran konservasi sumber daya alam dan ekosistemnya. Dalam menjalankan fungsi pelayanan informasi dan edukasi, dirumuskan program aktivitas, fasilitas dan koleksi yang terdapat dalam layanan eksisting dan pengembangannya.

Informasi yang dihasilkan Balai Besar TNGL cukup banyak dan beragam namun publikasi masih sangat terbatas dan belum optimal. Sementara kegiatan yang dilaksanakan oleh Balai Besar TNGL dan para mitra terus meningkat aktivitasnya di lapangan dan telah menghasilkan data dan informasi yang seharusnya segera dipublikasikan. Bentuk penyajian informasi dan koleksi juga masih sangat terbatas, perlu disesuaikan dengan perkembangan teknologi dan kebutuhan masyarakat.

Kebutuhan masyarakat khususnya yang bertujuan mengakses informasi telah meningkat dan membutuhkan fasilitas yang baik dalam bentuk fisik ruang, fasilitas, koleksi dan yang dilengkapi dengan teknologi terkini. Yang mana pada saat ini kondisi di lapangan 
belum mencukupi kebutuhan dan harapan pengelola untuk melayani masyarakat. Koleksi dan tata pameran Ruang Informasi dan Edukasi di Kantor Balai Besar Taman Nasional Gunung Leuser Medan saat ini belum dikelola dan dirancang dengan baik. Untuk pengembangan ke depan, disarankan untuk membuat perencanaan desain ruang dan tata pameran yang melibatkan seluruh pemangku kepentingan.

\section{F. Analisis Koleksi Ruang Informasi Dan}

\section{Edukasi}

\begin{tabular}{|c|c|c|c|}
\hline No & $\begin{array}{l}\text { Jenis } \\
\text { Informasi/ } \\
\text { Koleksi }\end{array}$ & $\begin{array}{c}\text { Bentuk } \\
\text { Penyajian / } \\
\text { Display }\end{array}$ & $\begin{array}{l}\text { Material Koleksi/Sifat } \\
\text { Penyajian Display/ Sifat } \\
\text { Komunikasi }\end{array}$ \\
\hline \multirow[t]{4}{*}{1} & $\begin{array}{l}\text { Sejarah } \\
\text { singkat TNGL }\end{array}$ & $\begin{array}{l}\text { Papan } \\
\text { Informasi }\end{array}$ & Semen cetak \\
\hline & & & Fix (Tetap) \\
\hline & & & Komunikasi 1 Arah \\
\hline & & & $\begin{array}{l}\text { Teks/Tulisan paragraf } \\
\text { panjang }\end{array}$ \\
\hline \multirow[t]{4}{*}{2} & Peta Kawasan & $\begin{array}{l}\text { Maket } \\
\text { Kawasan }\end{array}$ & Gypsum cetak \\
\hline & & & Fix (Tetap) \\
\hline & & & 1 Arah \\
\hline & & & Model 3D \\
\hline \multirow[t]{2}{*}{3} & $\begin{array}{l}4 \text { Satwa } \\
\text { Utama }\end{array}$ & $\begin{array}{l}\text { Model (skala } \\
\text { tidak } \\
\text { diketahui) }\end{array}$ & $\begin{array}{l}\text { Komposit cetak } \\
\text { Movable }\end{array}$ \\
\hline & & $\begin{array}{l}\text { Digital Print - } \\
\text { Standing } \\
\text { Banner }\end{array}$ & $\begin{array}{l}1 \text { Arah } \\
\text { Model } 3 \text { D dan 2D }\end{array}$ \\
\hline 5 & Flora & $\begin{array}{l}\text { Foto-foto } \\
\text { satwa yang } \\
\text { disusun } \\
\text { dalam lemari } \\
\text { display dan } \\
\text { diberi } \\
\text { keterangan } \\
\text { pada bagian } \\
\text { bawah }\end{array}$ & $\begin{array}{l}\text { Photo Paper dalam lemari } \\
\text { plywood + kaca } \\
\text { Fix (tetap) } \\
1 \text { Arah } \\
\text { 2D }\end{array}$ \\
\hline
\end{tabular}

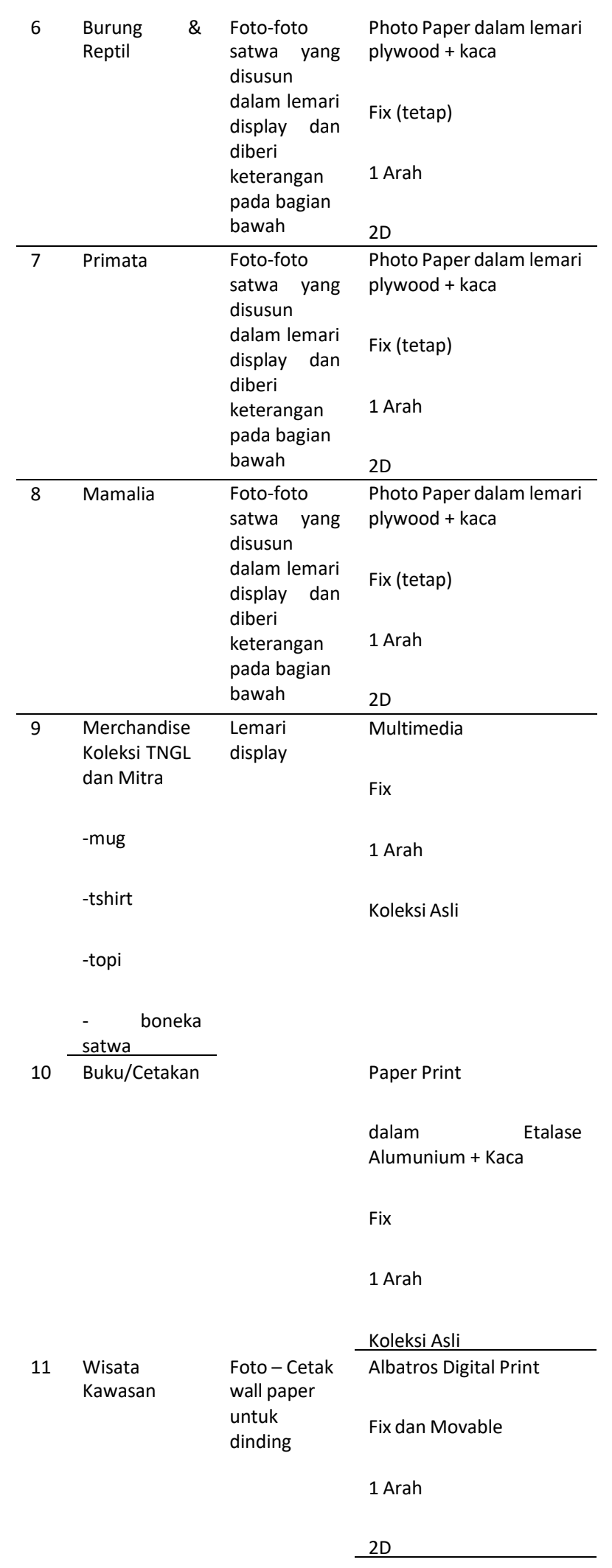




\section{G. Analisis Fungsional, Psikologis, Estetis,}

\section{Keamanan}

Berdasarkan teori tentang ruang informasi dan edukasi yang baik, memenuhi kriteria aspek fungsional, psikologis, estetis, keamanan, maka dapat disimpukan Tata Ruang dan Pameran di Ruang Informasi dan Edukasi di Kantor BBTNGL sebagai berikut:

1. Aspek Fungsional: Ruang eksisting kurang mampu mendukung kinerja pengelolaan, baik bagi petugas mauoun bagi pengunung.

2. Aspek psikologis: Pengelola dan pengunjung saat in leluasa bergerak karena sirkulasi yang cukup luas. Untuk kenyamanan visual, ruang ini cukup redup (kurang pencahayaan alami maupun pentaan pencahayaan buatan).

Display dan koleksi belum dilengkapi dengan pencahayaan khusus (spot lamp) sehingga nilai dari koleksi kurang dioptimalkan.

Kenyamanan thermal di ruang ini didukung dengan AC standing yang mampu mengkondisikan udara yang nyaman untuk beraktivitas. Namun unit AC ini sifatnya sementara, sedangkan AC split tidak berfungsi.

3. Aspek estetis : Secara estetis, selain finishing elemen interior yang ciri khas sebuah kantor pemerintaham, ruang ini juga dilengkapi gambar mural berbentuk awan pada langilangit. Juga mural 3 dimensi bertemakan alam hutan dan satwanya pada dinding.
4. Aspek Keamanan: Aspek keamanan sebagai antisipasi tindakan pencurian, ruang ini hanya dilengkapi dengan cctv, dan kunci manual untuk pintu-pintu. Sedangkan untuk aspek keselamatan, secara khusus tidak ada dalam perencanaannya.

\section{UCAPAN TERIMA KASIH}

Penelitian ini dapat terlaksana dan berjalan dengan bantuan berbagai pihak, untuk itu peneliti mengucapkan banyak terima kasih untuk pihak DPPM UNTAR, Pimpinan dan Staf Kantor Balai Besar Taman Nasional Gunung Leuser, WCS-IP untuk kerjasamanya dan telah memberikan bantuan dan kesediaan memberikan data-data yang diperlukan.

\section{DAFTAR PUSTAKA}

Kementerian Pendidikan dan Kebudayaan. "Membangun Budaya Literasi". Jurnal Akrab Vol. III Ed. I (September2017). 27 Oktober 2017. <http://sibopaksara.kemdikbud.go.id/uploads/ 2017- 09/tampilan-jurnal- akrab-vol-vii2016.pdf>.

Laurens, Joyce M. (2004). Arsitektur dan Perilaku Manusia.Jakarta: PT Grasindo

Snyder, J. (1984). Architectural Research. New York : VanNostrand Reinhold Company.

Réti, M., \& Lippai, E. (2011). Quality criteria for efficient learning environments in school buildings. Diambilkembali dari HUNGARIAN INSTITUTE FOR EDUCATIONAL RESEARCH AND DEVELOPMENT: http://ofi.hu/sites/default/files/ofipast/2011/11/Quali t y_criteria.pdf

Subagio, Rebecca Phylicia. Diana Thamrin. Anik Rakhmawati.(2018). Implementasi Konsep Taman Baca Dalam Redesain Interior Perpustakaan Umum Sebagai Sarana Edukasi Dan Rekreasi Di Kota Surabaya, JURNAL INTRA Vol. 6, No. 2, (2018) 